\title{
Suppression of synaptic plasticity by fullerenol in rat hippocampus in vitro
}

\author{
This article was published in the following Dove Press journal: \\ International Journal of Nanomedicine \\ 28 September 2016 \\ Number of times this article has been viewed
}

\author{
Xin-Xing Wang ${ }^{1,2, *}$ \\ Ying-Ying Zha ${ }^{3, *}$ \\ Bo Yang' \\ Lin Chen ${ }^{1,2}$ \\ Ming Wang ${ }^{1,2}$
}

'CAS Key Laboratory of Brain Function and Diseases, ${ }^{2}$ Auditory Research Laboratory, School of Life Sciences, University of Science and Technology of China, Hefei, Anhui, People's Republic of China; ${ }^{3}$ Cell Electrophysiology Laboratory, Wannan Medical College, Wuhu, Anhui, People's Republic of China

*These authors contributed equally to this work
Correspondence: Ming Wang School of Life Science, University of Science and Technology of China, Hefei, Anhui 230027, People's Republic of China Tel +8655163606458

Fax +8655 I 63601443

Email wming@ustc.edu.cn

\begin{abstract}
Fullerenol, a water-soluble fullerene derivative, has attracted much attention due to its bioactive properties, including the antioxidative properties and free radical scavenging ability. Due to its superior nature, fullerenol represents a promising diagnostic, therapeutic, and protective agent. Therefore, elucidation of the possible side effects of fullerenol is important in determining its potential role. In the present study, we investigated the acute effects of $5 \mu \mathrm{M}$ fullerenol on synaptic plasticity in hippocampal brain slices of rats. Incubation with fullerenol for 20 minutes significantly decreased the peak of paired-pulse facilitation and long-term potentiation, indicating that fullerenol suppresses the short- and long-term synaptic plasticity of region I of hippocampus. We found that fullerenol depressed the activity and the expression of nitric oxide (NO) synthase in hippocampus. In view of the important role of NO in synaptic plasticity, the inhibition of fullerenol on NO synthase may contribute to the suppression of synaptic plasticity. These findings may facilitate the evaluation of the side effects of fullerenol.
\end{abstract}

Keywords: fullerenol, hippocampal slice, nitric oxide synthase, synaptic plasticity, oxidative stress

\section{Introduction}

Several water-soluble fullerene derivatives have been synthesized by attaching polar functional groups (eg, $-\mathrm{OH},-\mathrm{COOH},-\mathrm{NH}_{2}$, and others) to the fullerene core for potential biomedical applications. ${ }^{1-4}$ Polyhydroxylated fullerene, known as fullerenol $\left(\mathrm{C}_{60}(\mathrm{OH})_{x}\right)$, has attracted considerable attention due to its antioxidative ${ }^{5-8}$ and antiproliferative activity. ${ }^{9,10}$ Hence, several studies reported that fullerenol and other fullerene derivatives may be used as drug carriers, ${ }^{11,12}$ neuroprotective agents, ${ }^{13,14}$ bioimaging contrast agents, ${ }^{15-19}$ and anticancer drugs. ${ }^{20-22}$ Despite convincing evidence of the potential value of fullerenol in biomedicine, ${ }^{23-28}$ the data pertaining to its side effects are inadequate.

Hippocampal synapse represents/is a model system to study the mechanisms of learning and memory in the brain. ${ }^{29}$ One of the classical hypotheses is that long-term potentiation (LTP), an activity-dependent strengthening of synapses, serves as a synaptic basis of learning and memory. $\mathrm{Ca}^{2+} / \mathrm{CaMKII}$ is a serine/threonine kinase with persistent enzymatic activity inducing $\mathrm{LTP}^{30}$ and is therefore considered as a molecular switch. Evidence suggests that NO mediates hippocampal synaptic plasticity, including LTP and long-term depression and, consequently, learning and memory. ${ }^{31-36} \mathrm{NO}$ is synthesized from 1-arginine by NOS in cells as a response to increased intracellular $\mathrm{Ca}^{2+}$ and is released upon synthesis. Our previous study has demonstrated that $5 \mu \mathrm{M}$ fullerenol could significantly protect hippocampal neurons against lead-induced neurotoxicity. ${ }^{37}$ In the present study, we investigated the acute effects of $5 \mu \mathrm{M}$ fullerenol on the synaptic plasticity of CA1 area in hippocampal slices and its underlying mechanisms. 


\section{Materials and methods}

Fullerenol preparation and

characterization

Fullerenol, $\left[\mathrm{C}_{60}(\mathrm{OH})_{x}(\mathrm{ONa})_{y}, y \approx 6-8, x+y \approx 24\right]$, purchased from the Materials and Electrochemical Research Corporation (Tucson, AZ, USA), was dissolved in double-distilled water at a concentration of $5 \mathrm{mM}(1,000$ times the final concentration) and stored at $4{ }^{\circ} \mathrm{C}$. Fullerenol was ultrasonically treated for 30 minutes and dissolved in artificial cerebrospinal fluid (ACSF) $(5 \mu \mathrm{M})$ just before experiments. The mean diameter and zeta potential of fullerenol in water were monitored using a Zetasizer Nano ZS90 (Malvern Instruments Ltd, Malvern, Worcestershire, UK), and the morphology of fullerenol was characterized by transmission electron microscopy using JEOL-2010 TEM (Japan Electron Optics Laboratory Co. Ltd., Tokyo, Japan) at an accelerating voltage of $200 \mathrm{kV}$.

\section{Experimental animals and treatment}

Wistar rats were purchased from SLAC Laboratory Animal Limited Liability Company (Shanghai, People's Republic of China). All animal treatments were strictly in accordance with the National Institutes of Health Guide for the Care and Use of Laboratory Animals (NIH publication No 80-23, revised in 1996) after approval from the Institutional Animal Care and Use Committee of University of Science and Technology of China. Animals were raised under controlled environmental conditions of an automatically controlled 12 hours light/dark cycles with lights on at 7.30 am, temperature of $21^{\circ} \mathrm{C} \pm 2{ }^{\circ} \mathrm{C}$, and humidity of $50 \% \pm 5 \%$. Distilled water and sterilized food were available ad libitum. Females were separated after pregnancy. The pups of both sexes were used for experiments at the age of 14-21 days. All efforts were made to minimize the number of animals used and their suffering.

\section{Slice preparation and recordings}

Hippocampal slices were prepared as described previously. ${ }^{38}$ Briefly, after the rats were decapitated, whole brains were removed immediately and submerged in oxygenated ACSF $\left(0^{\circ} \mathrm{C}-4^{\circ} \mathrm{C}\right)$, containing (in $\left.\mathrm{mM}\right) \mathrm{NaCl}, 124 ; \mathrm{KCl}, 5 ; \mathrm{NaH}_{2} \mathrm{PO}_{4}$, 1.25; $\mathrm{NaHCO}_{3}, 26 ; \mathrm{MgCl}_{2}, 1.25 ; \mathrm{CaCl}_{2}, 2.5$; dextrose (pH, 7.25-7.30; osmolarity, 295-310 mOsm $/ \mathrm{kg}$ ). Coronal sections measuring 300-400 $\mu \mathrm{m}$ in size, including sections of the hippocampus, were obtained continuously using a vibration microtome (VT1200; Leica, Wetzlar, Germany) and each slice was separated into two parts, including the right and left hippocampi. Slices were stored in ACSF at room temperature for at least 1 hour and then transferred to a recording chamber (BSC-HT; Medical Systems, Greenvale,
NY, USA), which was circulated through the chamber with $\operatorname{ACSF}\left(35^{\circ} \mathrm{C}\right)$ at a rate of $2 \mathrm{~mL} / \mathrm{min}$. One part was used for incubation of fullerenol (20 minutes), and the other part was incubated with normal ACSF.

Field excitatory postsynaptic potentials (fEPSPs) were recorded in the stratum radiatum of the $\mathrm{CA} 1$ area with a glass micropipette (1-3 M $\Omega$ ) filled with $2 \mathrm{M} \mathrm{NaCl}$, in response to electrical stimulation of the Schaffer collateral (SC) fibers using a bipolar stimulating electrode. Input/output curves were generated by systematic variation of the stimulus current (0.1-1.0 mA) to evaluate synaptic potency. Stimulus pulses were delivered at $0.05 \mathrm{~Hz}$, and three responses were averaged at each magnitude. Paired pulse facilitation (PPF) was evaluated by delivering pairs of identical stimuli with interpulse intervals (IPI) ranging from 10 to $500 \mathrm{~ms}$. The intensity of stimuli was adjusted to evoke about $40 \%$ of the maximum response of the population spike amplitude. Stimulus pairs were delivered at $0.05 \mathrm{~Hz}$, and three responses were averaged at each IPI. A stable recording of LTP was obtained for 40 minutes at $0.05 \mathrm{~Hz}$, followed by application of highfrequency stimulation (100 Hz; duration, 1 second). In the experiment using acute fullerenol treatment, baseline recording was obtained for 20 minutes, and then the slices were exposed to $5 \mu \mathrm{M}$ fullerenol solution for 20 minutes. Post-tetanic recordings were performed for 1 hour with single pulses at $0.05 \mathrm{~Hz}$. The responses were normalized to baseline values.

\section{Determination of the level of NOS and oxidative stress}

After incubation with normal ACSF or fullerenol, the hippocampal tissues were removed from slices and gently homogenized ( $10 \%$ weight/volume) in ice-cold saline. The homogenate was centrifuged at 4,000 rpm for 15 minutes at $4{ }^{\circ} \mathrm{C}$ and the supernatant collected for use. The protein concentrations were determined using a BCA protein assay kit (Beyotime, Shanghai, People's Republic of China). The activity of NOS, SOD, and the level of reduced glutathione hormone (GSH) and malondialdehyde (MDA) were measured using detection kits (Jiancheng Corp., Nanjing, People's Republic of China). All procedures were carried out according to the manufacturer's instructions. The absorbance at 530 $\mathrm{nm}$ (for NOS), $550 \mathrm{~nm}$ (for SOD), $420 \mathrm{~nm}$ (for GSH), and 532 $\mathrm{nm}$ (for MDA) was measured using an automated microplate spectrophotometer (Elx800; BioTek, Winooski, VT, USA).

\section{Western blot}

After administration of fullerenol or normal ACSF for 20 minutes, the hippocampal tissues were removed from the slices and crushed with a pestle in an ice-cold lysis buffer 
(Beyotime) with protein inhibitor cocktail (Roche Applied Science, Indianapolis, IN, USA) for 45 minutes. The homogenates were centrifuged at 12,000 rpm for 25 minutes at $4{ }^{\circ} \mathrm{C}$. The protein concentrations were determined using a BCA protein assay kit (Beyotime). The protein was mixed with sodium dodecyl sulfate sample buffer, heated to $100^{\circ} \mathrm{C}$ for 15 minutes, separated under reducing conditions on an $8 \%$ sodium dodecyl sulfate-polyacrylamide gel, and then transferred to polyvinylidene difluoride membranes (EMD Millipore, Billerica, MA, USA). The membrane was incubated with antibodies against NOS (Boster, Wuhan, People's Republic of China), CaMKII (Santa Cruz Biotechnology Inc., Dallas, TX, USA), p-CaMKII (Promega, Madison, WI, USA), GAPDH (EMD Millipore), and tubulin (Beyotime) overnight at $4{ }^{\circ} \mathrm{C}$ with horseradish peroxidase-linked secondary antibody (Promega) for 1 hour at room temperature. The bands were detected using chemiluminescence (GE Healthcare Bio-Sciences Corp., Piscataway, NJ, USA). The optical density of each band was determined using ImageJ software and normalized to that of GAPDH or tubulin.

\section{Immunofluorescence}

After 20 minutes incubation of normal ACSF or fullerenol, hippocampus slices were fixed with $4 \%$ paraformaldehyde in phosphate-buffered saline, blocked, and permeabilized with 5\% goat serum and $0.3 \%$ Triton X-100 (Sigma-Aldrich, St Louis, MO, USA), all in phosphate-buffered saline. Hippocampal sections $(40 \mu \mathrm{m})$ were sliced using a microtome (CM1950; Leica). For NOS immunofluorescence, the sections were incubated with mouse anti-NOS2 antibody (Boster) overnight at $4^{\circ} \mathrm{C}$ and with DAPI for 10 minutes at room temperature. The binding was visualized using the Alexa Fluor-conjugated secondary antibodies (Abcam, Cambridge, MA, USA). Sections were observed by confocal microscopy (Carl Zeiss Inc., Thornwood, NY, USA).

\section{Data analysis}

The slope of fEPSP represented the maximal slope obtained from the first deflection of the potential. Results of Western blot were statistically analyzed and compared by Student's $t$-test (paired, two-tailed). Other results were statistically analyzed using analysis of variance with Tukey's test. Data are presented as mean \pm standard error of mean. $P<0.05$ was considered statistically significant.

\section{Results \\ Characterization of fullerenol}

The images obtained using transmission electron microscopy revealed that fullerenol $(5 \mu \mathrm{M})$ was easily dispersed and aggregated in water (Figure 1A). The hydrodynamic size of
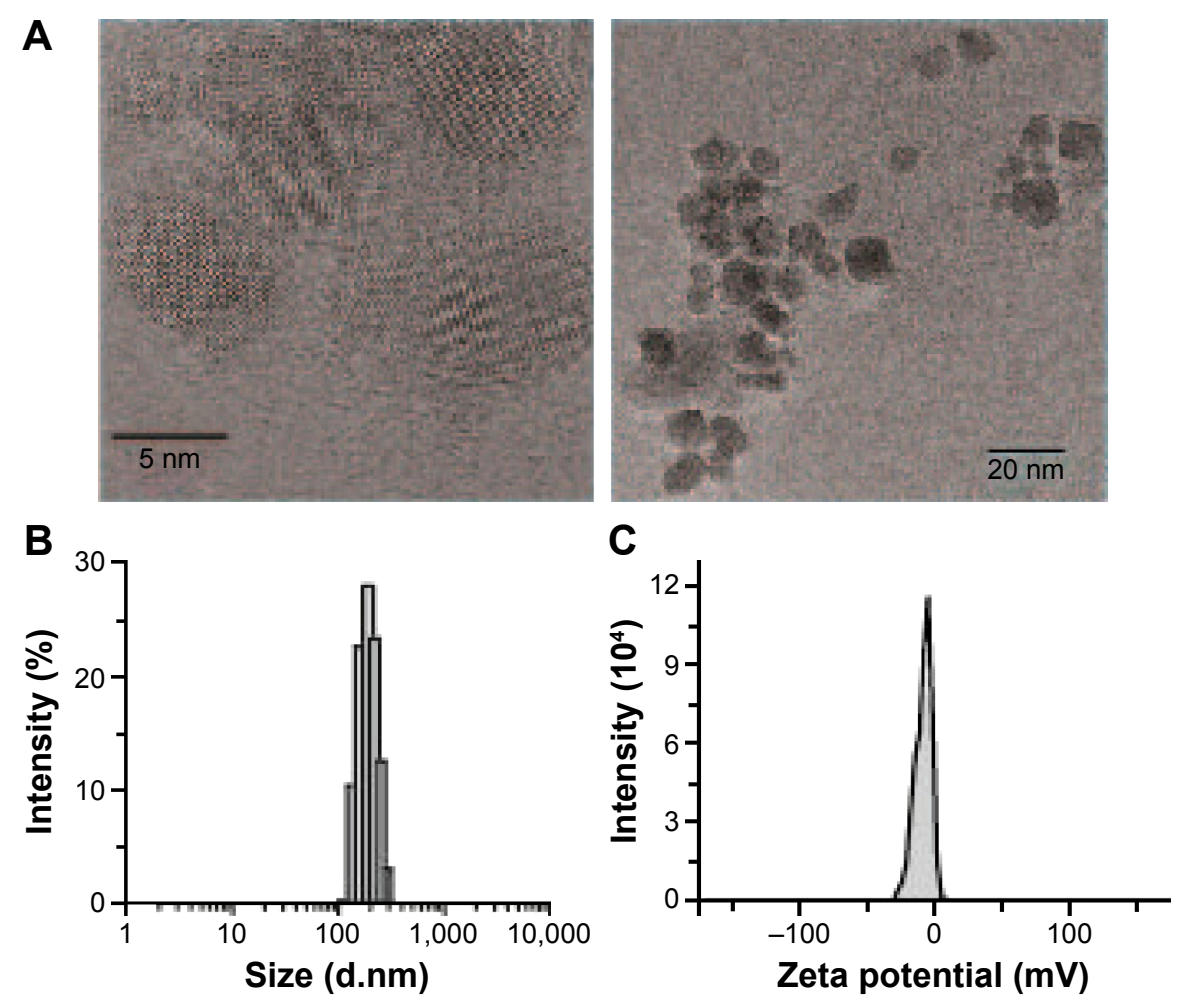

Figure I Characterization of fullerenol.

Notes: Transmission electron microscopic image of smaller fullerenol cores (A, left) and larger aggregates (A, right, I $\mu$ M fullerenol), size distributions (B), and zeta potentials (C) of fullerenol in water. 
fullerenol was $173.53 \pm 3.29 \mathrm{~nm}$ (Figure 1A and B), and the surface zeta potential of fullerenol was $-22.72 \pm 3.87 \mathrm{mV}$ (Figure 1C).

\section{Fullerenol suppressed PPF and LTP in the hippocampus}

Effects of fullerenol $(5 \mu \mathrm{M})$ exposure on basic synaptic transmission and short-term potentiation in the CA1 area of hippocampus were examined. After incubation with fullerenol for 20 minutes, no significant differences were observed in input/output curves between the control and fullerenol-treated groups ( $\mathrm{n}=6, P>0.05$, Figure $2 \mathrm{~A}$ and $\mathrm{B})$, suggesting that fullerenol exerted no recognizable effect on the basic synaptic transmission in hippocampus. We then investigated the effect of fullerenol on short-term synaptic plasticity. PPF is the facilitation of a second response when a synapse is stimulated twice with a short interstimulus interval (20-400 ms). The ratio of amplitude of fEPSP induced by second pulse stimuli to that of first pulse stimuli was measured upon increased IPI (10-500 ms) (Figure 2C).
The average peak facilitation in the control group was $201 \% \pm 18 \%$ at $30 \mathrm{~ms}$ IPI $(\mathrm{n}=8)$ and $151 \% \pm 8 \%$ in fullerenoltreated group at $40 \mathrm{~ms}$ IPI $(n=8)$. Fullerenol significantly decreased the peak of PPF $(P<0.05)$, suggesting that fullerenol suppressed the short-term synaptic plasticity from SC to CA1.

LTP is a long-lasting alteration in synaptic strength and plays a crucial role in learning and memory. ${ }^{39}$ We further investigated the acute effect of fullerenol on LTP in CA1 area. Fullerenol significantly suppressed the high-frequency stimulation-induced potentiation of excitatory postsynaptic potential (EPSP) in CA1 (control, 180\% $12 \%$; fullerenol, $117 \% \pm 7 \%, n=8, P<0.001$, Figure 2D), indicating that fullerenol suppressed the long-term synaptic plasticity in CA1. We also tested the effect on LTP of $1 \mu \mathrm{M}$ fullerenol; a lower concentration. Our data showed that fullerenol had no significant effect on the fEPSP slope in CA1 (control, $160 \% \pm 19 \%, \mathrm{n}=7$; fullerenol, $163 \% \pm 17 \%, \mathrm{n}=9, P>0.05$, Figure 2E), suggesting that the effect of fullerenol on LTP is concentration dependent.
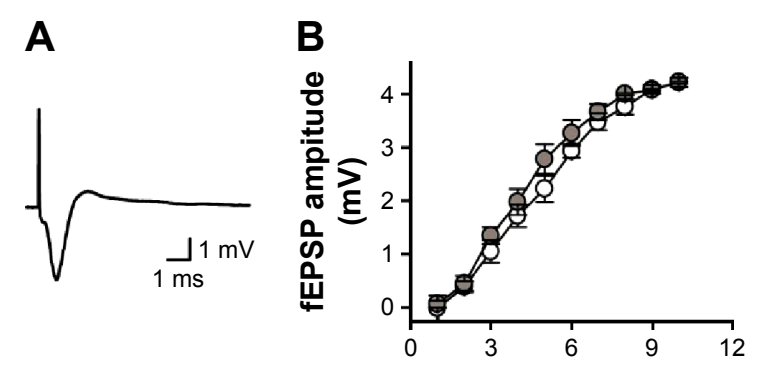

Stimulation intensity $(\mathrm{mA})$

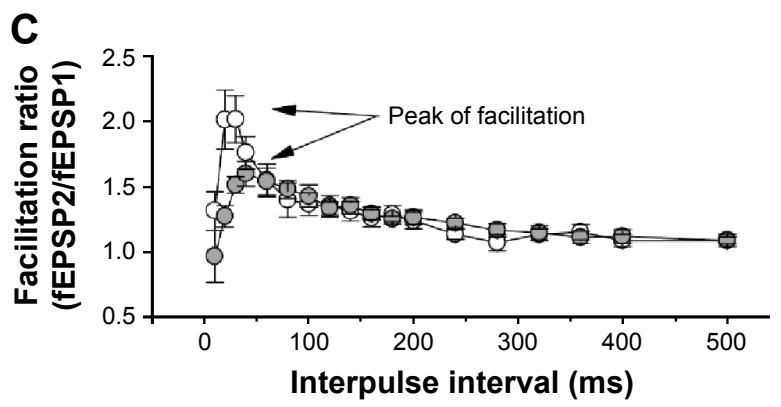

Control Fullerenol
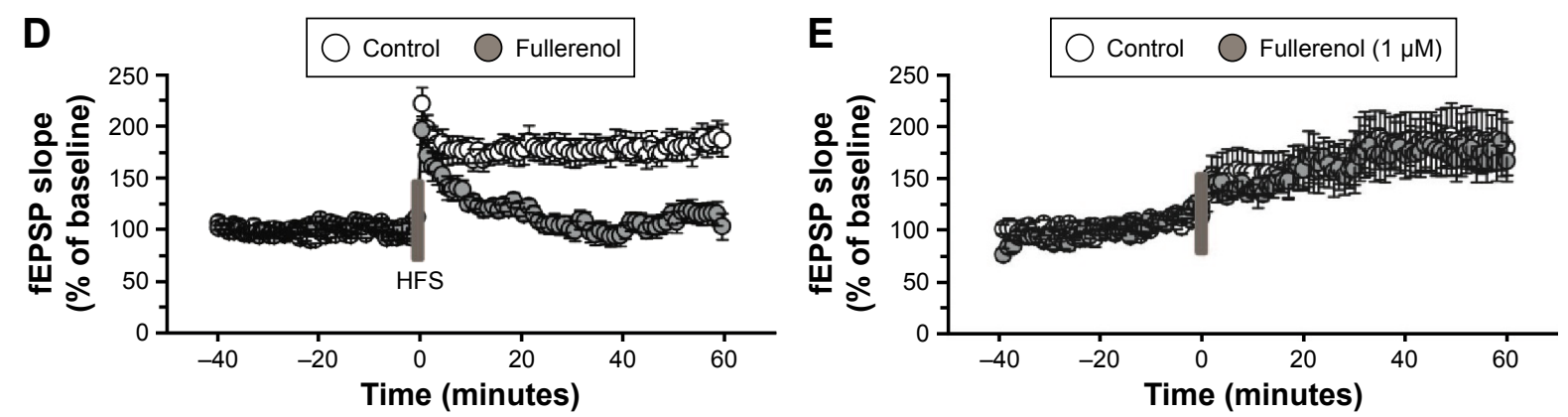

Figure 2 Effects of fullerenol on synaptic plasticity in the CAI area.

Notes: (A) Representative trace of fEPSP recorded from SC-CAI synapses. (B) Input/output curves after incubation of normal ACSF (six slices from six rats) and $5 \mu$ M fullerenol (six slices from six rats). Data were analyzed using a two-way repeated measures ANOVA, $P=0.08 \mathrm{I}$. (C) Mean PPF of fEPSP slope after incubation with normal ACSF (eight slices from eight rats) and $5 \mu \mathrm{M}$ fullerenol (eight slices from eight rats). Data were analyzed using a one-way repeated measures ANOVA followed by Tukey's post hoc test of the significance of PPF peaks, $P=0.021$. (D) LTP was induced by HFS ( 5 trains of 20 pulses at $200 \mathrm{~Hz}$ separated by I second, repeated six times at intervals of I minute) after treatment with normal ACSF (eight slices from eight rats) or fullerenol ( $5 \mu \mathrm{M}$, eight slices from eight rats). A two-way repeated measures ANOVA followed by Tukey's post hoc test was used $(P=0.0004)$. ( $E$ ) LTP induced after treatment with normal ACSF (seven slices from seven rats) or I $\mu M$ fullerenol (nine slices from nine rats). A two-way measures ANOVA followed by Tukey's post hoc test was used ( $P=0.9133)$. Fullerenol dissolved in ACSF was perfused 20 minutes prior to LTP induction. Data are presented as mean \pm SEM.

Abbreviations: ACSF, artificial cerebrospinal fluid; LTP, long-term potentiation; HFS, high-frequency stimulation; fEPSP, field excitatory postsynaptic potential; PPF, paired pulse facilitation; ANOVA, analysis of variance; SC, schaffer collateral; SEM, standard error of mean. 


\section{Suppression of synaptic plasticity independent of $\mathrm{p}$-CaMKII}

During synaptic potentiation, phosphorylation of CaMKII is essential for LTP induction. ${ }^{30,40}$ To investigate the mechanism of LTP suppression by fullerenol, we tested the level of p-CaMKII protein in hippocampus using Western blot. After 20 minutes of treatment with fullerenol $(5 \mu \mathrm{M})$, the level of $\mathrm{p}$-CaMKII/total CaMKII of fullerenol group was $161.11 \% \pm 57.22 \%$ (control set as $1, P>0.05$ ) (Figure 3 ). Although p-CaMKII showed little increase in fullerenoltreated group, no statistically significant differences were observed (Figure 3). These results suggested that fullerenol suppressed LTP independent of p-CaMKII level.

\section{Fullerene downregulated NOS activation and expression}

NO plays a critical role in the LTP of SC-CA1 pathway of hippocampus. Therefore, we tested the changes in hippocampal NOS after fullerenol treatment. Incubation with fullerenol for 20 minutes decreased the NOS in the hippocampus (Figure 4A) and reduced the total NOS to about $73 \%$ of the control level ( $n=5$, Figure 4B). We further investigated

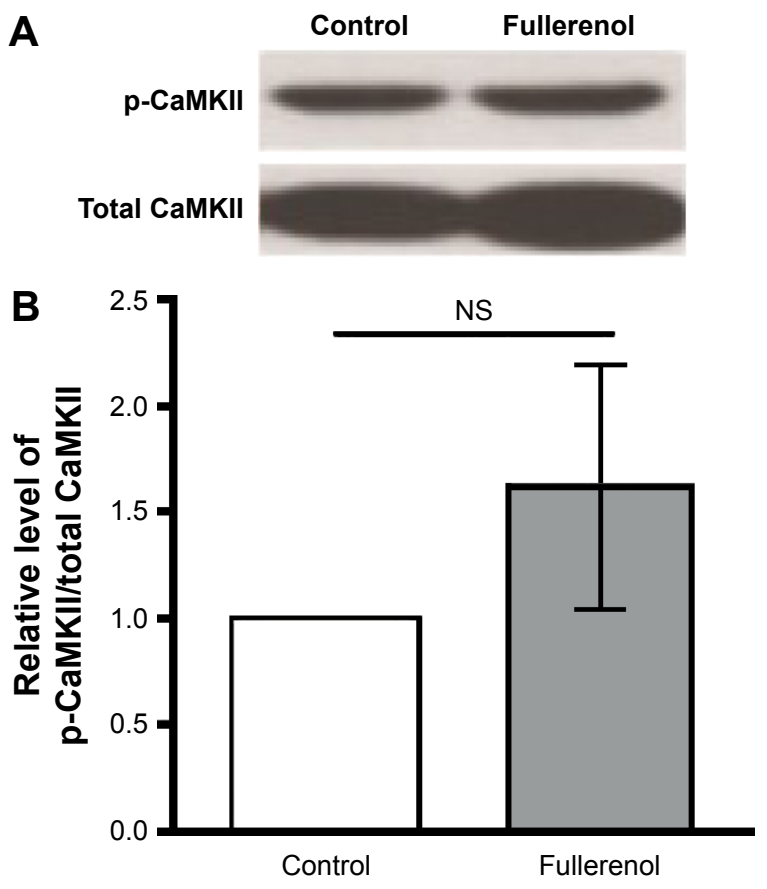

Figure 3 Fullerenol exhibited limited effect on p-CaMKII protein in the hippocampus. Notes: (A) Representative Western blots of $\mathrm{p}$-CaMKII and total CaMKII of hippocampal tissues harvested from control samples and samples incubated with fullerenol for 20 minutes. (B) Summarized Western blot results of p-CaMKII in slices normalized to total CaMKII in the hippocampal tissues harvested from control samples (four rats) and samples incubated with fullerenol for 20 minutes (four rats). A two-tailed Student's $t$-test was used $(P=0.934)$. GAPDH served as a loading control. Data are presented as mean \pm SEM. NS denotes $P>0.05$. Abbreviations: NS, nonsignificant; SEM, standard error of mean. the activity of NOS following fullerenol treatment of hippocampus. The NOS activity in the fullerenol-treated group was significantly lower than in the control (control, $1.21 \pm 0.09 \mathrm{U} / \mathrm{mg}$ protein; fullerenol, $1.64 \pm 0.06 \mathrm{U} / \mathrm{mg}$ protein, $\mathrm{n}=5, P<0.01$, Figure $4 \mathrm{C}$ ). These results suggest that fullerenol downregulated NOS, which may contribute to fullerenol-induced suppression of synaptic plasticity.

\section{Effects of fullerenol on oxidative stress}

In the present study, we tested various parameters related to oxidative stress, including the level of MDA and GSH and the activity of SOD. MDA is one of the major products of lipid peroxidation, and, therefore, indicates the rate and intensity of lipid peroxidation in the hippocampus. Our results show that the MDA concentration was significantly lower in the fullerenol-treated group (control, 6.35 $\pm 0.11 \mathrm{nmol} / \mathrm{mg}$ protein; ${ }^{1}$ fullerenol, $3.80 \pm 0.41 \mathrm{nmol} / \mathrm{mg}$ protein, $\mathrm{n}=5, P<0.01$, Figure 5A). The SOD concentration and GSH activity directly reflect tissue antioxidant levels. Our results showed no significant differences in the activity of SOD between the fullerenoltreated and control groups (control, 39.80 $\pm 0.64 \mathrm{U} / \mathrm{mg}$ protein; fullerenol, $39.78 \pm 0.81 \mathrm{U} / \mathrm{mg}$ protein, $\mathrm{n}=5, P>0.05$, Figure 5B). The GSH levels of the two groups showed a similar trend (control, $39.78 \pm 0.81 \mathrm{mg} / \mathrm{g}$ protein; fullerenol, $39.80 \pm 0.64 \mathrm{U} / \mathrm{mg}$ protein, $\mathrm{n}=5, P>0.05$, Figure $5 \mathrm{C}$ ).

\section{Discussion}

Our study provides direct evidence suggesting suppression of short- and long-term synaptic plasticity by acute fullerenol. First, it is widely recognized that PPF is a form of short-term, activity-dependent synaptic plasticity. ${ }^{41}$ It is attributed to residual intraterminal free $\mathrm{Ca}^{2+}$ derived from the first action potential facilitating release of neurotransmitters by the second stimulus. ${ }^{42}$ Our data showed that incubation with $5 \mu \mathrm{M}$ fullerenol for 20 minutes significantly decreased the PPF, which suggested that fullerenol treatment decreased the presynaptic neurotransmitter release. ${ }^{43}$ Additional experiments are needed to elucidate the mechanism of inhibition of the PPF. Second, LTP represents an important form of long-term synaptic plasticity. ${ }^{44}$ Our study showed that $5 \mu \mathrm{M}$ fullerenol inhibits LTP in hippocampus. However, the inhibition of LTP by fullerenol is concentration-dependent, because $1 \mu \mathrm{M}$ fullerenol has no significant effect on the LTP. To the best of our knowledge, this is the first evidence of suppression of synaptic plasticity by fullerenol.

It is noteworthy that $\mathrm{p}$-CaMKII plays a vital role in LTP induction. Although fullerenol suppressed LTP, no significant changes in $\mathrm{p}-\mathrm{CaMKII} / \mathrm{CaMKII}$ were observed in the 
A
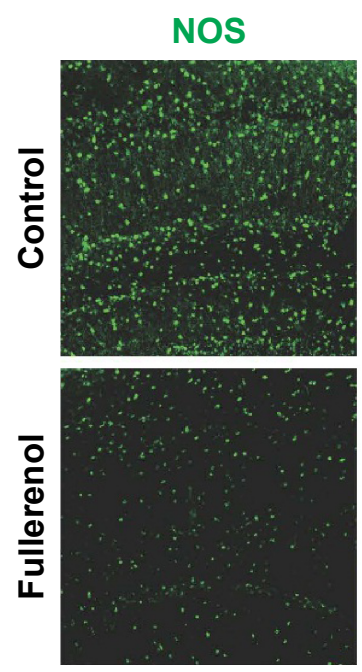

B

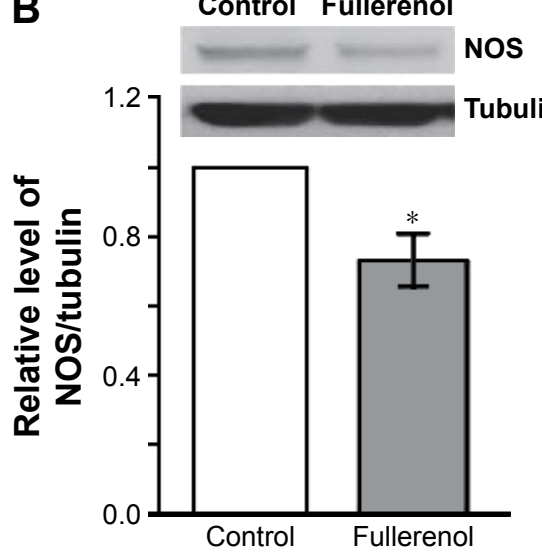

DAPI
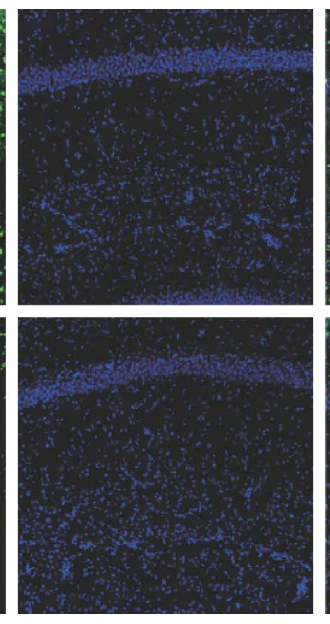

C
Merge
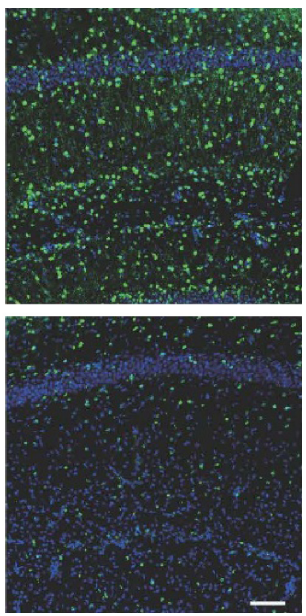

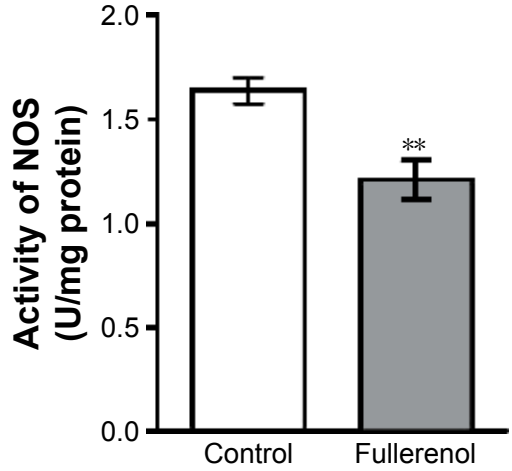

Figure 4 Fullerenol downregulated NOS in hippocampus.

Notes: (A) NOS (green) in the hippocampal neurons treated with normal ACSF (control) or fullerenol was analyzed by immunofluorescence using anti-NOS antibody. DAPI (blue) was used to label cell nuclei. The fluorescence ratio of NOS/DAPI was $61.11 \%$ in the control and $17.89 \%$ in the fullerenol-treated group. Scale bar $=100 \mu \mathrm{m}$. (B) NOS level in the hippocampus after incubation with ACSF (five rats) or fullerenol (five rats) was determined by Western blot. The bottom panel shows the level of NOS/tubulin compared with the average value of control (ACSF) set at I. Data were derived from five different samples and analyzed using two-tailed Student's $t$-test, $P=0.026$. (C) NOS activity of hippocampus after incubation of normal ACSF (five rats) or fullerenol (five rats) was detected using a protein assay kit. Data were analyzed using a one-way repeated measures ANOVA followed by Tukey's post hoc test, $P=0.005$. *Denotes $P<0.05$; **denotes $P<0.01$. Data are presented as mean $\pm S E M$.

Abbreviations: ANOVA, analysis of variance; ACSF, artificial cerebrospinal fluid; DAPI, 4',6-diamidino-2-phenylindole; SEM, standard error of mean.

A

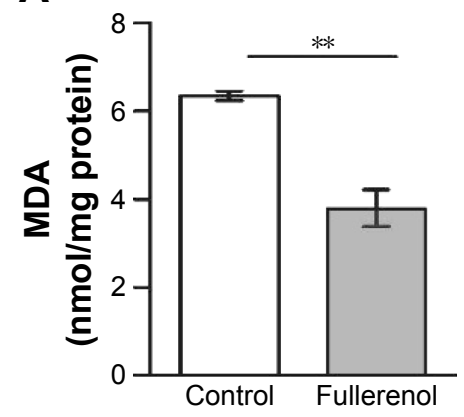

B

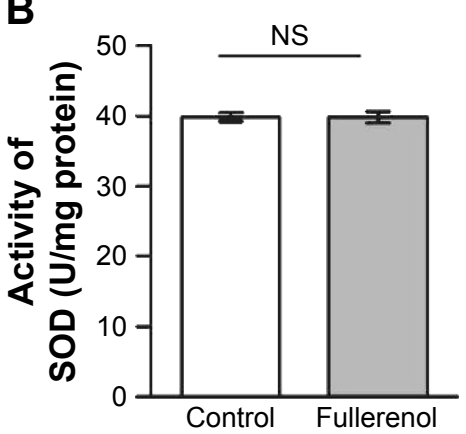

C

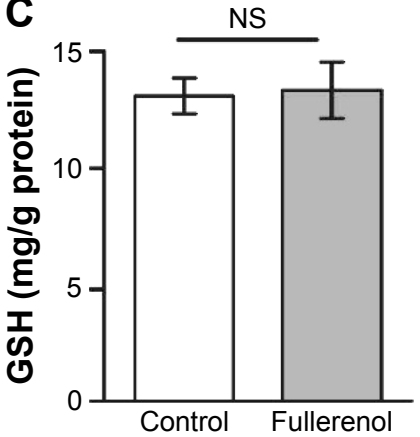

Figure 5 Effects of fullerenol on oxidative stress in hippocampus.

Notes: Effects of fullerenol on MDA content (A, five rats, using a one-way repeated measures ANOVA followed by Tukey's post hoc test, $P=0.0003$ ), SOD activity (B, five rats, using a one-way repeated measures ANOVA followed by Tukey's post hoc test, $P=0.991$ ), and GSH level (C, six rats, using a one-way repeated measures ANOVA followed by Tukey's post hoc test, $P=0.643$ ). Data are presented as mean \pm SEM. **Denotes $P<0.0$ I; NS denotes $P>0.05$.

Abbreviations: GSH, glutathione; MDA, malondialdehyde; ANOVA, analysis of variance; NS, nonsignificant; SEM, standard error of mean. 
present study suggesting that fullerenol acted independently of p-CaMKII. Meanwhile, NO generated by NOS formed cyclic guanosine monophosphate via soluble guanylyl cyclase ${ }^{45}$ and, in turn, activated cyclic guanosine monophosphate-dependent protein kinases. Behavioral experiments demonstrated that NO transmission was essential for short- ${ }^{33}$ and long-term memory. ${ }^{46}$ LTP in CA1 region of hippocampus is predominantly associated with memory formation. Several studies have shown NO affects LTP. NO released from postsynaptic neurons serves as a retrograde messenger and acts directly on the presynaptic neurons to produce LTP. ${ }^{47-50}$ Our results showed that fullerenol significantly inhibited the activity and expression of NOS in hippocampus. A previous study showed that fullerenol directly scavenged NO. ${ }^{7}$ Other studies showed that fullerene derivatives such as tris-malonyl- $\mathrm{C}_{60}$ also inhibited NOS activity and reduced the maximal velocity of product formation in rat pituitary cells in vitro. ${ }^{51}$ Fullerenol-induced reduction of NO synthesis and scavenging of $\mathrm{NO}$ may mediate the suppression of synaptic plasticity.

Oxidative stress plays a critical role in cognitive functions, ${ }^{52,53}$ including hippocampal synaptic plasticity. Our previous study of quantum dots indicated that this nanoparticle impaired synaptic transmission and plasticity in the rat dentate gyrus area of hippocampus via oxidative stress. ${ }^{54}$ Fullerenol may suppress the synaptic plasticity in hippocampus by triggering oxidative stress. However, such a mechanism was not possible in our experimental conditions since incubation with fullerenol for 20 minutes significantly reduced the concentration of MDA, suggesting that fullerenol inhibits oxidative damage in hippocampal neurons in vitro. Abundant evidence indicated that fullerenol exerted protective effects in neurons by scavenging free radicals, ${ }^{8,37,55}$ blocking glutamate receptors, and lowering the intracellular $\mathrm{Ca}^{2+}$ concentration. ${ }^{56}$ It is noteworthy that the antioxidative effect of fullerenol in the present experimental conditions did not depend on GSH or SOD levels.

Fullerenol has been investigated for potential application in chemotherapy, radiobiology, ${ }^{57}$ and as an agent targeting neurodegenerative diseases ${ }^{13,58}$ or inducing neuroprotection. ${ }^{8,37,56}$ Despite the convincing evidence suggesting the potential biomedical applications of fullerenol, our knowledge of the possible side effects, especially in neural tissues, is incomplete. Our previous study showed that fullerenol not only protects hippocampal neurons from lead-induced damage but also induces cell death in certain doses. ${ }^{37}$ In the present study, fullerenol suppressed synaptic plasticity and downregulated NOS, which is similar to the acute side effects of fullerenol in hippocampal tissue. Longterm studies investigating fullerenol suppression of synaptic plasticity in vivo are needed.

\section{Conclusion}

In the present study, we have shown that acute treatment with $5 \mu \mathrm{M}$ fullerenol suppressed short- and long-term synaptic plasticity, indicated by decreased PPF and LTP in hippocampal slices. Furthermore, the suppression by fullerenol was independent of the inhibition of p-CaMKII. Fullerenol significantly reduced the activity and quantity of NOS, which was probably responsible for the suppression of synaptic plasticity. Therefore, the study findings suggest the possible side effects of fullerenol and partly illustrate the underlying mechanisms, with potential implications for biomedical applications.

\section{Acknowledgments}

This work was supported by the National Basic Research Program of China (Grants 2012CB932502 and 2011CB504506), the National Natural Science Foundation of China (Grants 31170965, 81570915 and 81371503), the Natural Science Foundation of Anhui Province of China (Grant 1508085SQC203), and the Open Fund from CAS Key Laboratory of Brain Function and Diseases (2012-2013).

\section{Disclosure}

The authors report no conflicts of interest in this work.

\section{References}

1. Partha R, Conyers JL. Biomedical applications of functionalized fullerene-based nanomaterials. Int J Nanomedicine. 2009;4:261-275.

2. Bosi S, Da Ros T, Spalluto G, Prato M. Fullerene derivatives: an attractive tool for biological applications. Eur J Med Chem. 2003;38(11-12): 913-923.

3. Nakamura S, Mashino T. Water-soluble fullerene derivatives for drug discovery. J Nippon Med Sch. 2012;79(4):248-254.

4. Yan W, Seifermann SM, Pierrat P, Brase S. Synthesis of highly functionalized C60 fullerene derivatives and their applications in material and life sciences. Org Biomol chem. 2015;13(1):25-54.

5. Yang X, Li CJ, Wan Y, Smith P, Shang G, Cui Q. Antioxidative fullerol promotes osteogenesis of human adipose-derived stem cells. Int J Nanomedicine. 2014;9:4023-4031.

6. Xiao L, Aoshima H, Saitoh Y, Miwa N. Highly hydroxylated fullerene localizes at the cytoskeleton and inhibits oxidative stress in adipocytes and a subcutaneous adipose-tissue equivalent. Free Radic Biol Med. 2011; 51(7):1376-1389.

7. Mirkov SM, Djordjevic AN, Andric NL, et al. Nitric oxide-scavenging activity of polyhydroxylated fullerenol, $\mathrm{C} 60(\mathrm{OH}) 24$. Nitric Oxide. 2004; 11(2):201-207.

8. Dugan LL, Gabrielsen JK, Yu SP, Lin TS, Choi DW. Buckminsterfullerenol free radical scavengers reduce excitotoxic and apoptotic death of cultured cortical neurons. Neurobiol Dis. 1996;3(2):129-135. 
9. Mashino T, Nishikawa D, Takahashi K, et al. Antibacterial and antiproliferative activity of cationic fullerene derivatives. Bioorg Med Chem Lett. 2003;13(24):4395-4397.

10. Lu LH, Lee YT, Chen HW, Chiang LY, Huang HC. The possible mechanisms of the antiproliferative effect of fullerenol, polyhydroxylated C60, on vascular smooth muscle cells. Br J Pharmacol. 1998; 123(6):1097-1102.

11. Nakamura E, Isobe H. Functionalized fullerenes in water. The first 10 years of their chemistry, biology, and nanoscience. Acc Chem Res. 2003;36(11):807-815.

12. Chaudhuri P, Paraskar A, Soni S, Mashelkar RA, Sengupta S. Fullerenol-cytotoxic conjugates for cancer chemotherapy. ACS Nano. 2009;3(9):2505-2514.

13. Cai X, Jia H, Liu Z, et al. Polyhydroxylated fullerene derivative C(60) $(\mathrm{OH})(24)$ prevents mitochondrial dysfunction and oxidative damage in an MPP(+)-induced cellular model of Parkinson's disease. J Neurosci Res. 2008;86(16):3622-3634.

14. Dugan LL, Turetsky DM, Du C, et al. Carboxyfullerenes as neuroprotective agents. Proc Natl Acad Sci U S A. 1997;94(17):9434-9439.

15. Wharton T, Wilson LJ. Highly-iodinated fullerene as a contrast agent for X-ray imaging. Bioorg Med Chem. 2002;10(11):3545-3554.

16. Miyamoto A, Okimoto H, Shinohara H, Shibamoto Y. Development of water-soluble metallofullerenes as X-ray contrast media. Eur Radiol. 2006;16(5):1050-1053.

17. Mikawa M, Kato H, Okumura M, et al. Paramagnetic water-soluble metallofullerenes having the highest relaxivity for MRI contrast agents. Bioconjug Chem. 2001;12(4):510-514.

18. Bolskar RD, Benedetto AF, Husebo LO, et al. First soluble M@C60 derivatives provide enhanced access to metallofullerenes and permit in vivo evaluation of $\mathrm{Gd} @ \mathrm{C} 60[\mathrm{C}(\mathrm{COOH}) 2] 10$ as a MRI contrast agent. J Am Chem Soc. 2003;125(18):5471-5478.

19. Gaurav L, Balaji S. Multifunctional fullerene-and metallofullerenebased nanobiomaterials. Nano LIFE. 2013;03(03):22.

20. Chen C, Xing G, Wang J, et al. Multihydroxylated [ $\left.\mathrm{Gd}^{\circledR} \mathrm{C} 82(\mathrm{OH}) 22\right] \mathrm{n}$ nanoparticles: antineoplastic activity of high efficiency and low toxicity. Nano Lett. 2005;5(10):2050-2057.

21. Chen Z, Ma L, Liu Y, Chen C. Applications of functionalized fullerenes in tumor theranostics. Theranostics. 2012;2(3):238-250.

22. Prylutska SV, Burlaka AP, Klymenko PP, et al. Using water-soluble C fullerenes in anticancer therapy. Cancer Nanotechnol. 2011;2(1-6): $105-110$.

23. Johnson-Lyles DN, Peifley K, Lockett S, et al. Fullerenol cytotoxicity in kidney cells is associated with cytoskeleton disruption, autophagic vacuole accumulation, and mitochondrial dysfunction. Toxicol Appl Pharmacol. 2010;248(3):249-258.

24. Isakovic A, Markovic Z, Todorovic-Markovic B, et al. Distinct cytotoxic mechanisms of pristine versus hydroxylated fullerene. Toxicol Sci. 2006;91(1):173-183.

25. Sayes CM, Fortner JD, Guo W, et al. The differential cytotoxicity of water-soluble fullerenes. Nano Lett. 2004;4(10):1881-1887.

26. Zhao B, He YY, Bilski PJ, Chignell CF. Pristine (C60) and hydroxylated $[\mathrm{C} 60(\mathrm{OH}) 24]$ fullerene phototoxicity towards HaCaT keratinocytes: type I vs type II mechanisms. Chem Res Toxicol. 2008;21(5): 1056-1063.

27. Saathoff JG, Inman AO, Xia XR, Riviere JE, Monteiro-Riviere NA. In vitro toxicity assessment of three hydroxylated fullerenes in human skin cells. Toxicol In Vitro. 2011;25(8):2105-2112.

28. Grebowski J, Kazmierska P, Krokosz A. Fullerenols as a new therapeutic approach in nanomedicine. Biomed Res Int. 2013;2013:751913.

29. Roman FS, Truchet B, Marchetti E, Chaillan FA, Soumireu-Mourat B. Correlations between electrophysiological observations of synaptic plasticity modifications and behavioral performance in mammals. Prog Neurobiol. 1999;58(1):61-87.

30. Lisman J, Schulman H, Cline H. The molecular basis of CaMKII function in synaptic and behavioural memory. Nat Rev Neurosci. 2002; 3(3):175-190.
31. Harooni HE, Naghdi N, Sepehri H, Rohani AH. The role of hippocampal nitric oxide (NO) on learning and immediate, short- and long-term memory retrieval in inhibitory avoidance task in male adult rats. Behav Brain Res. 2009;201(1):166-172.

32. Yamada K, Noda Y, Nakayama S, et al. Role of nitric oxide in learning and memory and in monoamine metabolism in the rat brain. $\mathrm{Br} J$ Pharmacol. 1995;115(5):852-858.

33. Katzoff A, Ben-Gedalya T, Susswein AJ. Nitric oxide is necessary for multiple memory processes after learning that a food is inedible in aplysia. J Neurosci. 2002;22(21):9581-9594.

34. Kendrick KM, Guevara-Guzman R, Zorrilla J, et al. Formation of olfactory memories mediated by nitric oxide. Nature. 1997;388(6643): 670-674.

35. Bohme GA, Bon C, Lemaire M, et al. Altered synaptic plasticity and memory formation in nitric oxide synthase inhibitor-treated rats. Proc Natl Acad Sci U S A. 1993;90(19):9191-9194.

36. Susswein AJ, Katzoff A, Miller N, Hurwitz I. Nitric oxide and memory. Neuroscientist. 2004;10(2):153-162.

37. Zha YY, Yang B, Tang ML, et al. Concentration-dependent effects of fullerenol on cultured hippocampal neuron viability. Int J Nanomedicine. 2012;7:3099-3109.

38. Gong N, Zhang M, Zhang XB, Chen L, Sun GC, Xu TL. The aspirin metabolite salicylate enhances neuronal excitation in rat hippocampal CA1 area through reducing GABAergic inhibition. Neuropharmacology. 2008;54(2):454-463.

39. Abraham WC. Metaplasticity: tuning synapses and networks for plasticity. Nat Rev Neurosci. 2008;9(5):387.

40. Lisman J, Yasuda R, Raghavachari S. Mechanisms of CaMKII action in long-term potentiation. Nat Rev Neurosci. 2012;13(3):169-182.

41. Andersen P, Lomo T. Control of hippocampal output by afferent volley frequency. Prog Brain Res. 1967;27:400-412.

42. Katz B, Miledi R. The role of calcium in neuromuscular facilitation. J Physiol. 1968;195(2):481-492.

43. Schulz PE, Cook EP, Johnston D. Changes in paired-pulse facilitation suggest presynaptic involvement in long-term potentiation. J Neurosci. 1994;14(9):5325-5337.

44. Bliss TV, Collingridge GL. A synaptic model of memory: long-term potentiation in the hippocampus. Nature. 1993;361(6407):31-39.

45. Bredt DS, Snyder SH. Nitric oxide mediates glutamate-linked enhancement of cGMP levels in the cerebellum. Proc Natl Acad Sci US A. 1989; 86(22):9030-9033.

46. Kemenes I, Kemenes G, Andrew RJ, Benjamin PR, O’Shea M. Critical time-window for NO-cGMP-dependent long-term memory formation after one-trial appetitive conditioning. J Neurosci. 2002;22(4): 1414-1425.

47. Arancio O, Kiebler M, Lee CJ, et al. Nitric oxide acts directly in the presynaptic neuron to produce long-term potentiation in cultured hippocampal neurons. Cell. 1996;87(6):1025-1035.

48. Schuman EM, Madison DV. A requirement for the intercellular messenger nitric oxide in long-term potentiation. Science. 1991;254(5037): 1503-1506.

49. Zhuo M, Small SA, Kandel ER, Hawkins RD. Nitric oxide and carbon monoxide produce activity-dependent long-term synaptic enhancement in hippocampus. Science. 1993;260(5116):1946-1950.

50. Yang Y, Calakos N. Presynaptic long-term plasticity. Front Synaptic Neurosci. 2013;5:8.

51. Wolff DJ, Papoiu AD, Mialkowski K, Richardson CF, Schuster DI, Wilson SR. Inhibition of nitric oxide synthase isoforms by tris-malonyl-C(60)-fullerene adducts. Arch Biochem Biophys. 2000;378(2): 216-223.

52. Keller JN, Schmitt FA, Scheff SW, et al. Evidence of increased oxidative damage in subjects with mild cognitive impairment. Neurology. 2005;64(7):1152-1156.

53. Wang J, Markesbery WR, Lovell MA. Increased oxidative damage in nuclear and mitochondrial DNA in mild cognitive impairment. J Neurochem. 2006;96(3):825-832. 
54. Tang M, Li Z, Chen L, et al. The effect of quantum dots on synaptic transmission and plasticity in the hippocampal dentate gyrus area of anesthetized rats. Biomaterials. 2009;30(28):4948-4955.

55. Ye S, Chen M, Jiang Y, et al. Polyhydroxylated fullerene attenuates oxidative stress-induced apoptosis via a fortifying Nrf2-regulated cellular antioxidant defence system. Int J Nanomedicine. 2014;9:2073-2087.

56. Jin H, Chen WQ, Tang XW, et al. Polyhydroxylated C(60), fullerenols, as glutamate receptor antagonists and neuroprotective agents. $J$ Neurosci Res. 2000;62(4):600-607.
57. Xiao L, Takada H, Gan X, Miwa N. The water-soluble fullerene derivative "Radical Sponge" exerts cytoprotective action against UVA irradiation but not visible-light-catalyzed cytotoxicity in human skin keratinocytes. Bioorg Med Chem Lett. 2006;16(6):1590-1595.

58. Yin JJ, Lao F, Fu PP, et al. The scavenging of reactive oxygen species and the potential for cell protection by functionalized fullerene materials. Biomaterials. 2009;30(4):611-621.

\section{Publish your work in this journal}

The International Journal of Nanomedicine is an international, peerreviewed journal focusing on the application of nanotechnology in diagnostics, therapeutics, and drug delivery systems throughout the biomedical field. This journal is indexed on PubMed Central, MedLine, CAS, SciSearch $\AA$, Current Contents ${ }^{\circledR} /$ Clinical Medicine,
Journal Citation Reports/Science Edition, EMBase, Scopus and the Elsevier Bibliographic databases. The manuscript management system is completely online and includes a very quick and fair peer-review system, which is all easy to use. Visit http://www.dovepress.com/ testimonials.php to read real quotes from published authors.

Submit your manuscript here: http://www.dovepress.com/international-journal-of-nanomedicine-journal 